\title{
Cardamonin exerts a protective effect against autophagy and apoptosis in the testicles of diabetic male rats through the expression of Nrf2 via p62-mediated Keap-1 degradation
}

\author{
Shereen M. Samir ${ }^{1}$, Mahmoud Elalfy ${ }^{2}$, Eman Mohamad El Nashar ${ }^{3,4}$, Mansour A. Alghamdi ${ }^{5,6}$, Eman Hamza', \\ Mohamed Saad Serria ${ }^{7}$, and Mona G. Elhadidy ${ }^{1,8 * *}$ \\ ${ }^{1}$ Department of Medical Physiology, College of Medicine, Mansoura University, Mansoura 35511, Egypt, ${ }^{2}$ Department of Forensic Medicine and Toxicology, \\ Faculty of Veterinary Medicine, Mansoura University, Mansoura 35511, Egypt, ${ }^{3}$ Department of Anatomy, Faculty of Medicine, King Khalid University, Abha \\ 61421, Saudi Arabia, ${ }^{4}$ Department of Histology and Cell Biology, College of Medicine, Benha University, Benha 13511, Egypt, ${ }^{5}$ Department of Anatomy, College \\ of Medicine, King Khalid University, Abha 61421, Saudi Arabia, ${ }^{6}$ Genomics and Personalized Medicine Unit, College of Medicine, King Khalid University, Abha \\ 61421, Saudi Arabia, 'Medical Biochemistry Department, College of Medicine, Mansoura University, Mansoura 35511, Egypt, ${ }^{8}$ Department of Medical Physiol- \\ ogy, College of Medicine, Al-Baha University, Al-Baha 65525, Saudi Arabia
}

\section{ARTICLE INFO}

Received December 24, 2020

Revised May 8, 2021

Accepted May 27, 2021

*Correspondence

Mona G. Elhadidy

E-mail:mona.gaber2012@yahoo.com

Key Words

Apoptosis

Autophagy

Glucose transporter

Gonadotropins

Insulin sensitivity

Reproductive capacity

\begin{abstract}
Cardamonin (CARD) is a chalconoid with anti-inflammatory and antioxidant properties, and it is present in several plants. We sought to explore whether CARD exerts any positive effects against hyperglycemia-induced testicular dysfunction caused by type 2 diabetes and aimed to identify its possible intracellular pathways. Adult male rats were subdivided into six groups: control, CARD, diabetic (DM), $\mathrm{DM}+$ glibenclamide (GLIB), DM + CARD and DM + GLIB + CARD. Type 2 DM induced a significant increase in blood glucose and insulin resistance, along with diminished serum insulin, testosterone and gonadotropins levels, which were associated with the impairment of key testicular androgenic enzymes and cellular redox balance. Administration of CARD at a dose of $80 \mathrm{mg} / \mathrm{kg}$ for 4 weeks effectively normalized all of these alterations, and the improvement was confirmed by epididymal sperm analysis. After treatment with CARD, the pathological changes in spermatogenic tubules were markedly improved. Significantly, CARD upregulated testicular glucose transporter-8 (GLUT-8) expression and had inhibitory effects on elevated autophagy markers and caspase- 3 immunoreactive cells. Furthermore, our results revealed that CARD was able to attenuate damage via activation of Nrf2 through the p62dependent degradation of testicular anti-Kelch-like ECH-associated protein-1 (Keap1). In conclusion, this study suggests that CARD provides protection against diabetic stress-mediated testicular damage. The use of CARD with conventional anti-diabetic therapy was associated with improved efficacy compared with conventional therapy alone.
\end{abstract}

\section{INTRODUCTION}

Diabetes mellitus (DM) is a chronic metabolic disease, and the number of patients with either type 1 or type 2 is increasing dramatically worldwide, especially among young individuals [1].
Type $2 \mathrm{DM}$ (T2DM) is considered to be the most common type of DM, accounting for more than $90 \%$ of all cases, and it results mainly from a combination of insulin resistance and its impaired secretion. It is often associated with disturbed lipid and lipoprotein metabolism [2]. Previous studies strongly support that T2DM of the Creative Commons Attribution Non-Commercial License, which permits unrestricted non-commercial use, distribution, and reproduction in any medium, provided the original work is properly cited. Copyright $\odot$ Korean J Physiol Pharmacol, pISSN 1226-4512, elSSN 2093-3827
Author contributions: M.G.E. and S.M.S. conceived and designed the research, conducted the experiment, analyzed data and wrote the manuscript. Processing and analysis of Western blot were done by M.E. E.M.E.N. and M.A.A. contributed to writing the manuscript and funding for publication. E.H. and M.S.S. performed the biochemical and real-time PCR analysis. All authors have accepted responsibility for the entire content of this manuscript and approved its submission. 
is accompanied by serious complications that affect different organs, including those of the reproductive system $[3,4]$.

Except in a few areas of the world, diabetes is more prevalent in males than females, particularly in middle-aged populations [5]. One of the most prominent complications of DM is testicular hypofunction, as normal spermatogenic and steroidogenic functions require glucose homeostasis [6]. As a result, the majority of patients with uncontrolled diabetes suffer from a variety of sexual dysfunction symptoms, such as impotence, loss of libido, abnormal semen analysis and low levels of testosterone [7]. To date, the underlying molecular mechanisms of DM-induced male testicular dysfunction have remained elusive. Autophagy is a molecular mechanism that promotes the function and survival of cells, such as pancreatic beta cells and insulin-target tissues [8]. Abnormal autophagy can lead to many complications in diseases, including DM, neurodegeneration and cancer [9]. Many studies have suggested that excessive autophagy plays a protective role against oxidative stress in pancreatic beta cells [10]. However, constitutively activated autophagy has detrimental effects on pancreatic beta cells, resulting in autophagic cell death [11].

As confirmed by previous studies, conventional management of DM either with insulin or synthetic oral hypoglycemic drugs (OHDs) can produce undesirable side effects and does not achieve a powerful protective effect against the development of many complications related to diabetes. Therefore, the search for more effective and safer hypoglycemic agents has continued to be an important area of active research. Herbal remedies are being used as new hypoglycemic agents with minimal or no side effects and relatively low costs relative to synthetic OHDs [12].

In the last decades, extensive efforts have been dedicated to research on chalcones and their biological activities in many disorders, such as anti-tuberculous activity [13], tyrosine kinase inhibition [14] and lethal effects in human and murine cancer lines $[15,16]$. The chalcone cardamonin $\left(2^{\prime}, 4^{\prime}\right.$-dihydroxy-6'-methoxychalcone; CARD) is one of the main elements of Alpinia katsumadai Hayata (Zingiberaceae) seeds. Tram et al. [17] demonstrated that the phenolic constituents of Zingiberaceae seeds have antibacterial, anti-inflammatory and potent therapeutic activities, as well as low systemic toxicity. Yamamoto et al. [18] discovered the hypoglycemic and antioxidant properties of CARD in myotube cell lines. It was reported that abnormal excessive autophagy plays a prominent role in hastening diabetic-induced reproductive injury. Therefore, the aim of this study was to reveal the possible effects of CARD in the prevention of diabetesinduced testicular dysfunction in male rats and determine its role in apoptosis, oxidative stress and autophagy.

\section{METHODS}

\section{Experimental animals}

In this study, we used male Sprague-Dawley rats. Animals were housed in the Medical Experimental Research Center (MERC) animal house, Mansoura University, Faculty of Medicine, Egypt, in controlled environmental conditions (temperature of $22 \pm 2^{\circ} \mathrm{C}$ and humidity of $55 \% \pm 5 \%$ with a $12: 12 \mathrm{~h}$ light and dark cycle). They were acclimatized for one week, during which they were provided with normal commercial pellet diet chow with free access to tap water. The protocol of this experimental study was conducted according to the Guide for the Care and Use of Laboratory Animals (8th edition, National Academies Press). In addition, our local committee of animal care for the Mansoura Faculty of Medicine approved this protocol (Code number: R.20.07.941).

\section{Experimental design}

Forty-two adult male Sprague-Dawley rats (3-4 months old, 180-220 g) were randomly divided into 6 groups, each of which contained 7 rats: the normal control group, fed normal rat chow; CARD, fed normal rat chow and treated with cardamonin by oral gavage $(80 \mathrm{mg} / \mathrm{kg} /$ day for 4 weeks) [19]; and four diabetic groups (DM: untreated diabetic group; DM + GLIB: diabetic rats treated with glibenclamide [1 mg/kg/day] [20]; DM + CARD: diabetic rats treated with cardamonin $[80 \mathrm{mg} / \mathrm{kg} /$ day]; and DM + GLIB + CARD: diabetic rats treated with both glibenclamide and cardamonin at the aforementioned doses). Glibenclamide and cardamonin were obtained from Sigma Chemical Co. (St. Louis, MO, USA). All groups were maintained on their diet regimens for 4 weeks. Then, after the induction of type $2 \mathrm{DM}$, the treated diabetic groups were administered their treatments by oral gavage for another 4 weeks. The treated diabetic groups remained on the same normal chow diet as was used in the other groups.

\section{Induction of type 2 diabetes}

For the induction of T2DM, all diabetic groups were fed a highfat diet (HFD) (58\% fat, $17 \%$ carbohydrate and $25 \%$ protein as a percentage of total Kca) for the initial 4-week period [21], while the two non-diabetic groups were kept on a normal diet ad libitum (5\% fat, $53 \%$ carbohydrate and $23 \%$ protein, with a total calorific value of $25 \mathrm{~kJ} / \mathrm{kg}$ ) [22]. Four weeks of HFD induced insulin resistance in the rats, and then after $12 \mathrm{~h}$ of fasting, a single low dose of streptozotocin (STZ) $(35 \mathrm{mg} / \mathrm{kg}$ ) (Sigma Chemical Co.) dissolved in citrate buffer ( $\mathrm{pH} 4.4$ ) was administered intraperitoneally (i.p.) in the lower right quadrant of the abdomen. This was followed by the administration of $5 \%$ glucose solution to prevent hypoglycemic shock. During the same period, the non-diabetic rats were injected intraperitoneally with citrate buffer alone $(\mathrm{pH}$ 
4.5) at a dose of $1 \mathrm{~mL} / \mathrm{kg}$. Blood glucose concentrations were measured $72 \mathrm{~h}$ after STZ injection using the One Touch Blood Glucose Monitoring System (Life Scan, Milpitas, CA, USA) using blood obtained by tail vein puncture. Rats with plasma glucose $\geq$ $300 \mathrm{mg} / \mathrm{dl}$ were considered diabetic and selected for our study.

After the treatment and experimentation period, the rats were weighed and then anesthetized with sodium thiopental $(35 \mathrm{mg} /$ $\mathrm{kg}$ i.p. injection) [23]. Then, blood samples were collected directly from the heart for fasting blood glucose, insulin and hormonal assays. In addition, the testes were dissected, and epididymides and sperm samples were obtained from the cauda epididymis. The right testes were preserved in Bouin's solution for histopathological and immunohistochemical examinations. The left ones were weighed and divided into three parts. One part was stored at $-20^{\circ} \mathrm{C}$ for the detection of enzyme activities, and another part was preserved in RNAlater Stabilization Solution (Thermo Fisher Scientific, Waltham, MA, USA) at $4^{\circ} \mathrm{C}$ overnight before being stored at $-80^{\circ} \mathrm{C}$ until the isolation of total RNA and subsequent real-time RT-PCR. The third part was stored at $-80^{\circ} \mathrm{C}$ for the subsequent Western blot assay (Fig. 1).

\section{Measurement of fasting blood glucose and insulin levels and Homeostatic Model Assessment of Insulin Resistance (HOMA-IR)}

The animals were fasted for $24 \mathrm{~h}$ before the end of the experiment, and blood glucose levels ( $\mathrm{mg} / \mathrm{dl}$ ) were measured using a glucose oxidase method (Contournext, Parsippany, NJ, USA). Fasting insulin levels $(\mu \mathrm{U} / \mathrm{ml})$ were assessed by a radio immune assay kit (Abcam, Cambridge, MA, USA). HOMA-IR was calculated through the following equation: (fasting blood glucose levels $\times$ fasting blood insulin levels) / 405 [24].

\section{Biochemical analysis in serum}

Serum levels of gonadotrophin hormones, follicle stimulating hormone (FSH) [25], luteinizing hormone (LH) [26] and testosterone [27] were determined using the Rat ELISA kit purchased from Abcam Company, UK, using the sandwich ELISA principle.

\section{Estimation of key testicular androgenic enzyme activities}

Testicular tissues were homogenized in $5 \mathrm{mM}$ potassium phosphate that contained 20\% spectroscopic grade glycerol, and $1 \mathrm{mM}$ EDTA was added at a tissue concentration of $100 \mathrm{mg} / \mathrm{ml}$ to the homogenizing mixture. The solution was centrifuged at 10,000 $\times \mathrm{g}$ for $30 \mathrm{~min}$. From that mixture, $1 \mathrm{ml}$ of the supernatant was obtained for the measurement of testicular $\Delta^{5}, 3 \beta$-hydroxysteroid dehydrogenase ( $\Delta^{5}-3 \beta$-HSD) and 17 $\beta$-hydroxysteroid dehydrogenase (17 $\beta$-HSD) activities. These enzyme activities were assessed by standard methods [28] as per the standard protocol. At 340 $\mathrm{nm}$, optical density was recorded at 30 -s intervals for $3 \mathrm{~min}$.

\section{Estimation of testicular TBARS and antioxidants activities}

The supernatant of the testicular homogenate was also used for the detection of thiobarbituric acid reactive substance (TBARS) activity using a spectrophotometer cuvette, and the absorbance was read at $535 \mathrm{~nm}$ using the method of Ohkawa et al. [29]. Catalase activity was detected in the homogenate supernatant using the methodology of Aebi [30], and the absorbance was read at 240 $\mathrm{nm}$. Reduced glutathione (GSH) was determined in the prepared samples according to the method described by Beutler et al. [31]. Superoxide dismutase (SOD) activity was detected in the testicular homogenate in accordance with Kakkar et al. [32] and was read using a spectrophotometer at $420 \mathrm{~nm}$.

\section{Sperm sample from epididymis}

Sperm samples were collected by surgically exposing the cauda

\begin{tabular}{|c|c|c|c|c|}
\hline Grouns & Acclimatization & High fat diet & STZ & Normal diet with treatment \\
\hline & 1 week & 4 weeks & $\# \quad 3$ days & 4 weeks \\
\hline Normal group & $(+)$ & $(-)$ & $(-)$ & Normal diet only \\
\hline CARD group & $(+)$ & $(-)$ & $(-)$ & $(+)$ \\
\hline DM group & $(+)$ & $(+)$ & $(+)$ & Normal diet only \\
\hline $\mathbf{D M}+\mathbf{G L I B}$ & $(+)$ & $(+)$ & $(+)$ & $(+)$ \\
\hline DM + CARD & $(+)$ & $(+)$ & $(+)$ & $(+)$ \\
\hline $\mathbf{D M}+\mathbf{G L I B}+\mathbf{C A R D}$ & $(+)$ & $(+)$ & $(+)$ & $(+)$ \\
\hline
\end{tabular}

Fig. 1. Time schedule for the experimental design. CARD, normal rats supplemented with cardamonin; $D M$, untreated diabetic group; $D M+G L I B$, diabetic rats treated with glibenclamide; DM + CARD, diabetic rats treated with cardamonin; DM + GLIB + CARD, diabetic rats treated with both glibenclamide and cardamonin. "Represents the administration of STZ. 
epididymis after scarification. Samples were taken from the distal part of the cauda epididymis and collected using the diffusion method [33]. In short, this method was performed by placing the excised and trimmed epididymis in a Petri dish with $5 \mathrm{ml}$ of Hanks' Balanced Salt Solution composed of $2.0 \mathrm{~g} / \mathrm{L}$ bovine serum albumin, 4.2 g/L N-2-Hydroxyethyl piperazine-N-2 ethansulfonic acid, $0.35 \mathrm{~g} / \mathrm{L}$ sodium bicarbonate, $0.1 \mathrm{~g} / \mathrm{L}$ sodium pyruvate, $0.025 \mathrm{~g} / \mathrm{L}$ soybean trypsin inhibitor and $0.9 \mathrm{~g} / \mathrm{L}$ d-glucose (Sigma Chemical Company), $\mathrm{pH}$ 7.4. The lumen of the distal portion of the cauda epididymal tube was pierced by a scalpel blade at various locations while taking care to avoid cutting blood vessels. Sperm quickly start to diffuse from the lumen of the tubule due to the internal fluid pressure. Once turbidity appeared, after around $30 \mathrm{~s}$, the epididymal tissue was moved away, and the dish was placed in a tissue culture incubator $\left(5 \% \mathrm{CO}_{2}, 34^{\circ} \mathrm{C}\right)$ for $\sim 15 \mathrm{~min}$ until performing the subsequent analysis of sperm motion. The sample was placed on a glass slide and covered with a cover slip. Under a light microscope, the motile spermatozoa were counted, and the percentage of viable spermatozoa was determined, followed by eosin-nigrosine staining according to the standard protocol; the number was expressed as a percentage after counting 100 sperms in each field [34]. These parameters were analyzed by computer-assisted sperm analysis (CASA) using VideoTest ZooSperm (rat module) software (Russia).

\section{Histopathological and immunohistochemical examination}

One day after the right testicles were fixed in Bouin's solution, the tissues were dehydrated in alcohol, treated with xylene and embedded in paraffin wax. Sections with a thickness of $6 \mu \mathrm{m}$ were sliced using a rotary microtome. Sections of testes were processed for H\&E staining for histopathological measurement of the seminiferous tubule diameter and visualization of germ cell morphology.

The immunohistochemical staining was performed according to [35]. The serial sections were dewaxed, hydrated and immersed in an antigen retrieval solution (EDTA solution, $\mathrm{pH}$ 8). They were then treated with $0.3 \%$ hydrogen peroxide and protein block, followed by incubation with caspase-3 primary antibody (1:100 dilution; R\&D Systems Inc., Minneapolis, MN, USA). The slides were rinsed three times with PBS, incubated with anti-mouse IgG secondary antibodies (EnVision + System HRP; Dako, Carpinteria, CA, USA) for $30 \mathrm{~min}$ at room temperature, visualized with di-aminobenzidine commercial kits (Liquid DAB + Substrate Chromogen System; Dako) and finally counterstained with Mayer's hematoxylin. As a negative control, the primary antibody was replaced by normal mouse serum. The labelling index of caspase-3 was expressed as the percentage of positive cells per 1,000 counted cells in about 8 high-power fields.

\section{Total RNA isolation and real-time PCR analysis}

Total RNA was extracted from frozen testes with RNA TRIzol (Invitrogen, Carlsbad, CA, USA) according to manufacturer instructions. RNA concentrations and purities were quantified using a Nanodrop ND-1000 spectrophotometer. Complementary DNA (cDNA) was synthesized from total RNA using the RNA PCR kit (TaKaRa, DaLian, China) according to the manufacturer's protocol. TransStart Top Green qPCR SuperMix kit was used for qPCR analysis (initial template denaturation at $95^{\circ} \mathrm{C}$ for $5 \mathrm{sec}$, followed by $40 \mathrm{cycles}$ of $95^{\circ} \mathrm{C}$ for $30 \mathrm{sec}, 55^{\circ} \mathrm{C}$ for $30 \mathrm{sec}$ and $72^{\circ} \mathrm{C}$ for $30 \mathrm{sec}$ ). The cycle threshold values were used to calculate the normalized expression of Nrf2, Keap-1, p62, beclin-1, LC3, and GLUT- 8 against $\beta$-actin using the Q-Gene software [36]. The sequences of the primer pairs are as follows: $\beta$-actin, 5'TAGTTGCGTTACACCCTTTCTTG-3'/5'-TCACCTTCACCGTTCCAGTT-3'; Nrf2, 5'-AGCATAGAGCAGGACATGGAGCAAGT-3'/5'-CTGGCTGGCATCATCAGTGGAGAGG-3'; Keap-1, 5'-CTGCATCCACCACAGCAGCGT-3'/5'-GTGCAGCACACAGACCCCGGC-3'; p62, 5'-TGGTGCTACTGCCTCTTCTCA-3'/5'-GGGTTACTTTGGTCCGCTTT-3'; Beclin-1, 5'-TGAGGGATGGA AGGGTCTAAG-3'/5' GCCTGGGCTGTGGTAAGTAATC-3'; LC3, 5'-CATGAGCGAGTTGGTCAAGAT-3'/5'-TCGTCTTTCTCCTGCTCGTAG-3'; GLUT-8 5'-TCATGGACAGAGCAGGGCG3'/5'GCCAGCCAGGCCAGCCCCA-3'. $\beta$-Actin was used as the internal reference gene for the normalization of gene expression levels. PCR was analyzed using the $\Delta \Delta$ cycle threshold method, as described previously [37].

\section{Western blot analysis}

To determine the protein expression, equal amounts of frozen testicular tissues were homogenized in 2\% SDS (Sigma) with Lysing Matrix D (MP Biomedicals, Santa Ana, CA, USA) using a high-speed benchtop homogenizer system, FastPrep 24 MP (3 times for $20 \mathrm{sec}$ in every cycle). The homogenates were clarified by centrifugation at $15,000 \times \mathrm{g}$ at $4^{\circ} \mathrm{C}$ for $15 \mathrm{~min}$ to obtain supernatants. Total protein contents were determined according to the BCA protein assay procedure (Thermo Scientific, Warsaw, Poland), using bovine serum albumin (BSA) (BioShop, Burlington, ON, Canada) as a calibration standard. Furthermore, $30 \mu \mathrm{g}$ of proteins were separated by $10 \%$ SDS-PAGE under reducing conditions, and the proteins were transferred onto a polyvinylidene difluoride membrane (Merck Millipore, Oakville, ON, Canada). Next, the membranes were washed, and nonspecific binding sites were blocked with $1 \%$ BSA in TBST buffer $(20 \mathrm{mM}$ Tris- $\mathrm{HCl} \mathrm{pH}$ $7.5,137 \mathrm{mM} \mathrm{NaCl}, 0.1 \%$ Tween 20$)$ at room temperature $\left(21^{\circ} \mathrm{C}\right)$ for $1 \mathrm{~h}$, and then they were incubated overnight with the following primary antibodies: anti-Kelch-like ECH-associated protein-1 (Keap-1), anti-LC3I, anti-LC3II (1:1,000; Cell Signaling, Beverly, MA, USA), anti-Nrf2, anti-p62 (1:1,000, Abcam) and beclin-1 
(1:1,000, Thermo Scientific) prepared in 1\% BSA in TBST. Following incubation with the primary antibody, the membranes were washed with TBST four times for $5 \mathrm{~min}$ and incubated for $1 \mathrm{~h}$ with horseradish peroxidase-conjugated secondary antibodies. The blots were visualized using the ECL Western Blotting kit (BioRad, Hercules, CA, USA) and the Fusion Fx7 (Viber Lourant, Marne La Vallée, France) system. A densitometric analysis was performed using GelQuantNET software. The bands were quantified and normalized to their corresponding $\beta$-actin bands [38].

\section{Statistical analysis}

The data were analyzed using Statistical Package for Social Science software version 17 (SPSS Inc., Chicago, IL, USA) and expressed as the mean and standard deviation. One-way ANOVA followed by post-hoc Tukey was used to compare groups. $p$-values of $\leq 0.05$ were considered significant.

\section{RESULTS}

\section{Effects of CARD on weights of the body and testicles in type 2 diabetic rats}

The results shown in Table 1 show a significant decrease in the diabetic rats' final body weights and testicular weights $(\mathrm{p}<0.001)$ in comparison with the control group results. However, all treated groups showed a significant improvement in both parameters $(\mathrm{p}<0.001)$ relative to the untreated diabetic control. The most prominent improvements in these two parameters were observed in the combined treatment group relative to the monotherapy groups. Normal non-diabetic rats that were administered CARD showed non-significant changes in both weights when compared with the control group.

\section{Effects of CARD on the levels of blood glucose, serum insulin and HOMA-IR}

The results in Table 1 reveal a significant increase in the fasting blood glucose level $(p<0.001)$ concomitant with a significant decrease in the serum insulin level $(\mathrm{p}<0.001)$ of untreated diabetic rats when compared with the control group. On the contrary, administration of CARD to diabetic rats resulted in a significant decrease in the level of fasting blood glucose $(p<0.001)$ and a significant increase in the level of insulin $(p<0.001)$ when compared with the untreated diabetic group. This improvement with CARD was reflected in the insulin sensitivity index, as detected by HOMA-IR and reported in Table 1 . However, the observed effects were very prominent in the combined treatment rats when compared with rats that received the other treatments. However, the normal non-diabetic rats that received CARD showed nonsignificant changes in these biochemical parameters as compared with the control group.

\section{Effects of CARD on the serum levels of testosterone and pituitary gonadotropins}

The serum concentrations of testosterone, LH and FSH were significantly decreased in the untreated diabetic group $(\mathrm{p}<0.001)$ when compared with the control group, as shown in Table 2. Conversely, all treated diabetic groups showed a significant increase in these hormones relative to the untreated diabetic rats, with the greatest improvement observed in the combined treatment group. Furthermore, the CARD-treated non-diabetic rats showed a significant increase in these hormonal levels when compared with the control group.

\section{Effect of CARD on epididymal sperm analysis}

Table 2 shows a significant decrease in both the sperm number and motility $(\mathrm{p}<0.001)$ in the non-treated diabetic rats as com-

Table 1. Effects of CARD on the final body weight, testicular weight, blood glucose, insulin levels, and HOMA-IR in all experimental groups

\begin{tabular}{|c|c|c|c|c|c|}
\hline Variable & $\begin{array}{l}\text { Final body weight } \\
\text { (gm) }\end{array}$ & $\begin{array}{l}\text { Testicular weight } \\
\text { (gm) }\end{array}$ & $\begin{array}{l}\text { Fasting blood glucose } \\
(\mathrm{mg} / \mathrm{dl})\end{array}$ & $\begin{array}{l}\text { Fasting insulin } \\
\quad(\mu \mathrm{IU} / \mathrm{ml})\end{array}$ & HOMA-IR \\
\hline Control & $282.56 \pm 1.76$ & $1.68 \pm 0.09$ & $74.26 \pm 2.98$ & $15.04 \pm 1.31$ & 2.76 \\
\hline CARD & $280.06 \pm 2.85$ & $1.71 \pm 0.08$ & $72.15 \pm 2.25$ & $16.09 \pm 1.02$ & 2.87 \\
\hline DM & $221.33 \pm 2.33^{*}$ & $1.09 \pm 0.07^{*}$ & $384.27 \pm 3.54^{*}$ & $5.78 \pm 1.28^{*}$ & 5.48 \\
\hline $\mathrm{DM}+\mathrm{GLIB}$ & $255.66 \pm 3.51^{*, \#}$ & $1.29 \pm 0.08^{*, \#}$ & $143.32 \pm 4.76^{*, \#}$ & $12.61 \pm 1.18^{*, \#}$ & 4.46 \\
\hline $\mathrm{DM}+\mathrm{CARD}$ & $241.733 \pm 2.59^{*, \#, \$}$ & $1.49 \pm 0.08^{*, \#, \$}$ & $157.74 \pm 3.79^{*, \#, \$}$ & $11.89 \pm 1.19^{*, \#, \$}$ & 4.63 \\
\hline $\mathrm{DM}+\mathrm{GLIB}+\mathrm{CARD}$ & $272.41 \pm 2.31^{*, \#, \$, @ ~}$ & $1.56 \pm 0.09^{\#, \$, @ ~}$ & $97.72 \pm 4.37^{*, \#, \$, @ ~}$ & $14.57 \pm 1.40^{\#, \$, @ ~}$ & 3.51 \\
\hline
\end{tabular}

Values are presented as mean \pm SD. CARD, normal rat supplemented with cardamonin; HOMA-IR, homeostatic model assessment of insulin resistance; DM, untreated diabetic group; $D M+G L I B$, diabetic rats treated with glibenclamide; DM + CARD, diabetic rats treated with cardamonin; DM + GLIB + CARD, diabetic rats treated with both glibenclamide and cardamonin. Test used: One-way ANOVA followed by post-hoc Tukey's test. *Represents significance compared with the control group; ${ }^{*}$ represents significance compared with the DM group; ${ }^{\$}$ represents significance compared with the DM + GLIB group; ${ }^{\circledR}$ represents significance compared with the DM + CARD group. 
Table 2. Effects of CARD on the serum levels of testosterone, FSH, LH, sperm number and motility in all experimental groups

\begin{tabular}{|c|c|c|c|c|c|}
\hline Variable & Testosterone (ng/ml) & $\mathrm{FSH}(\mathrm{ng} / \mathrm{ml})$ & $\mathrm{LH}(\mathrm{ng} / \mathrm{ml})$ & Sperm number $\left(\times 10^{6}\right)$ & Sperm motility (\%) \\
\hline Control & $4.89 \pm 0.97$ & $6.22 \pm 0.64$ & $7.21 \pm 0.90$ & $167.46 \pm 6.45$ & $13.60 \pm 1.43$ \\
\hline CARD & $5.13 \pm 0.83$ & $6.60 \pm 0.84$ & $7.55 \pm 0.49$ & $171.22 \pm 6.82$ & $14.84 \pm 1.42$ \\
\hline DM & $1.25 \pm 0.21^{*}$ & $2.92 \pm 0.65^{*}$ & $4.11 \pm 0.89 *$ & $42.22 \pm 8.37^{*}$ & $3.18 \pm 0.88^{*}$ \\
\hline $\mathrm{DM}+\mathrm{GLIB}$ & $2.34 \pm 0.65^{*, \sharp}$ & $3.54 \pm 0.64^{*, \#}$ & $4.62 \pm 0.89^{*, \#}$ & $87.10 \pm 6.33^{*, \#}$ & $5.33 \pm 0.75^{*, \sharp}$ \\
\hline $\mathrm{DM}+\mathrm{CARD}$ & $3.02 \pm 0.64^{*, \#, \$}$ & $4.48 \pm 0.63^{*, \#, \$}$ & $5.16 \pm 0.90^{*, \#, \$}$ & $100.35 \pm 7.10^{*, \#, \$}$ & $6.88 \pm 0.89^{*, \#, \$}$ \\
\hline $\mathrm{DM}+\mathrm{GLIB}+\mathrm{CARD}$ & $3.85 \pm 0.53^{\#, \$, @ ~}$ & $5.18 \pm 0.87^{\#, \$, @ ~}$ & $6.29 \pm 0.89^{\#, \$, @ ~}$ & $138.24 \pm 8.95^{*, \#, \$, @}$ & $10.87 \pm 1.39^{*, \#, \$, @}$ \\
\hline
\end{tabular}

Values are presented as mean \pm SD. CARD, normal rat supplemented with cardamonin; FSH, follicle stimulating hormone; LH, luteinizing hormone; DM, untreated diabetic group; $\mathrm{DM}+\mathrm{GLIB}$, diabetic rats treated with glibenclamide; DM + CARD, diabetic rats treated with cardamonin; DM + GLIB + CARD, diabetic rats treated with both glibenclamide and cardamonin. Test used: One-way ANOVA followed by post-hoc Tukey's test. *Represents significance compared with the control group; ${ }^{*}$ represents significance compared with the DM group; ${ }^{\$}$ represents significance compared with the DM + GLIB group; ${ }^{\circledR}$ represents significance compared with the DM + CARD group.
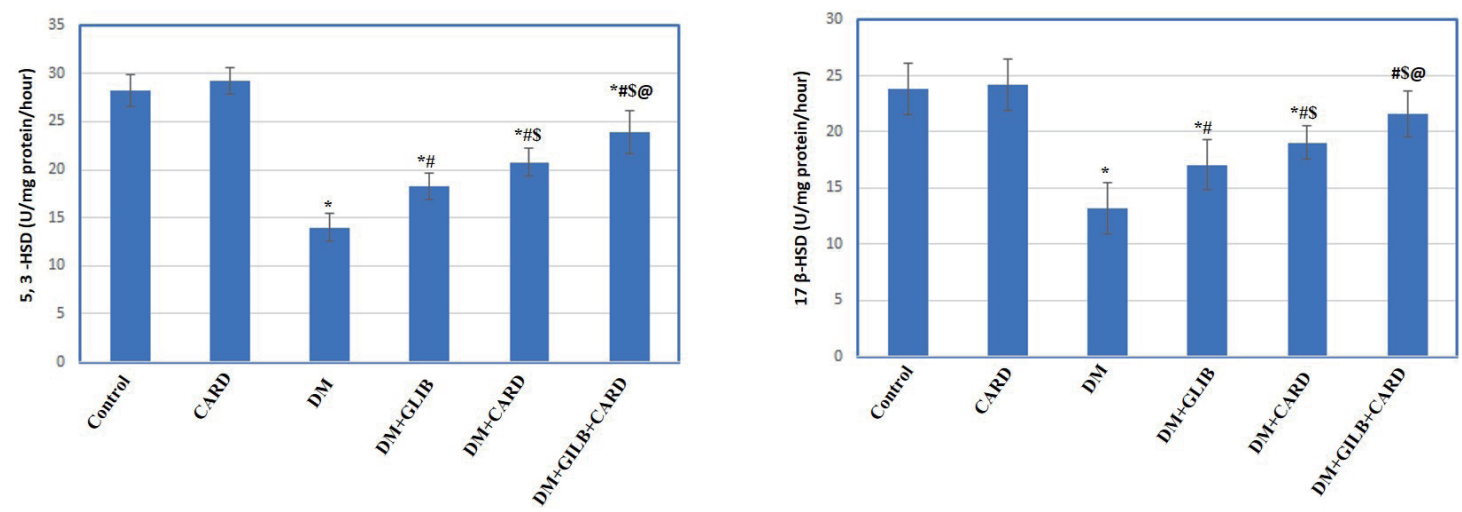

Fig. 2. Effect of cardamonin on key testicular steroid enzymes in different experimental groups. Values are presented as mean \pm SD. CARD, normal rats treated with cardamonin; $D M$, untreated diabetic group; $D M+G L I B$, diabetic rats treated with glibenclamide; DM + CARD, diabetic rats treated with cardamonin; DM + GLIB + CARD, diabetic rats treated with both glibenclamide and cardamonin. Tests used: One-way ANOVA followed by post-hoc Tukey's test. $p<0.001$. *Represents significance compared with the control group; " represents significance compared with the DM group; ${ }^{\$}$ represents significance compared with the DM + GLIB group; ${ }^{\circledR}$ represents significance compared with the DM + CARD group.

pared with the controls. However, these adverse effects of diabetes on both sperm parameters were significantly minimized in the CARD-treated group $(\mathrm{p}<0.001)$, with the most beneficial effect observed in rats that received the combined treatment relative to the other treated diabetic groups. Furthermore, the non-diabetic rats treated with CARD showed a significant increase in the epididymal sperm analysis results $(\mathrm{p}<0.01)$ as compared with values from the controls.

\section{Effect of CARD on testicular function-related markers}

Since the diabetic group showed a deterioration in the serum testosterone level, we determined the activity of two key testicular enzymes that are responsible for the biosynthesis of testosterone $\left(\Delta^{5}, 3 \beta-H S D\right.$ and $\left.17 \beta-H S D\right)$ in order to explore the possible mechanism related to this impairment. The activities of these testicular enzymes were significantly diminished in the diabetic group $(\mathrm{p}<$ 0.001 ) when compared with the control. However, administration of CARD significantly reversed these diabetic changes, as shown in Fig. 2. Among all treated groups, the diabetic rats that received the combined treatment of CARD and GLIB exhibited the maximum improvement in the activities of these key testicular androgenic enzyme. Moreover, the CARD group showed a significant increase in both enzyme activities relative to the control group.

\section{Effect of CARD on testicular antioxidant enzymes and oxidative stress marker}

Fig. 3 reveals a significant decrease in the non-treated diabetic testicular levels of GSH, CAT, and SOD ( $p<0.001)$ with an elevated level of the oxidative stress-related marker TBARS $(p<0.001)$ in comparison with findings for the control group. In all treated groups, the activities of antioxidant enzymes were significantly increased $(\mathrm{p}<0.001)$, which was associated with a significant decrease in the level of TBARS ( $p<0.001)$ when compared with the untreated diabetic group. However, the combined treatment group showed the most prominent effect relative to the other treated diabetic groups. Normal non-diabetic rats that were administered CARD showed a marked enhancement in antioxidant enzyme activities and improvement in the oxidative stress marker 

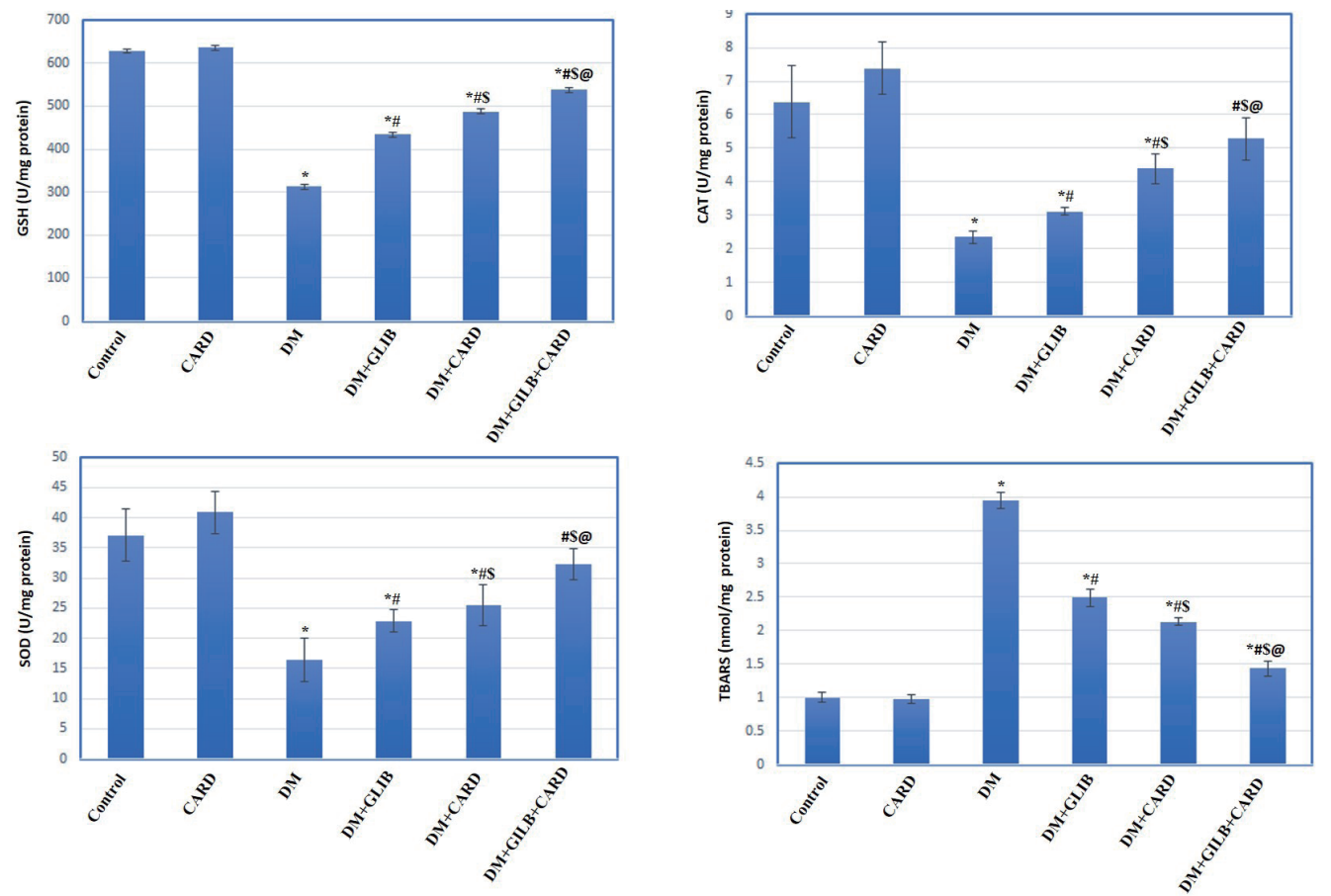

Fig. 3. Effect of cardamonin on testicular oxidative stress markers and antioxidant activities in different experimental groups. Values are presented as mean \pm SD. CARD, normal rats treated with cardamonin; DM, untreated diabetic group; DM + GLIB, diabetic rats treated with glibenclamide; $\mathrm{DM}+\mathrm{CARD}$, diabetic rats treated with cardamonin; DM + GLIB + CARD, diabetic rats treated with both glibenclamide and cardamonin. Tests used: One-way ANOVA followed by post-hoc Tukey's test. $p<0.001$. * Represents significance compared with the control group; ${ }^{*}$ represents significance compared with the DM group; ${ }^{\dagger}$ represents significance compared with the DM + GLIB group; ${ }^{\circledR}$ represents significance compared with the DM + CARD group.
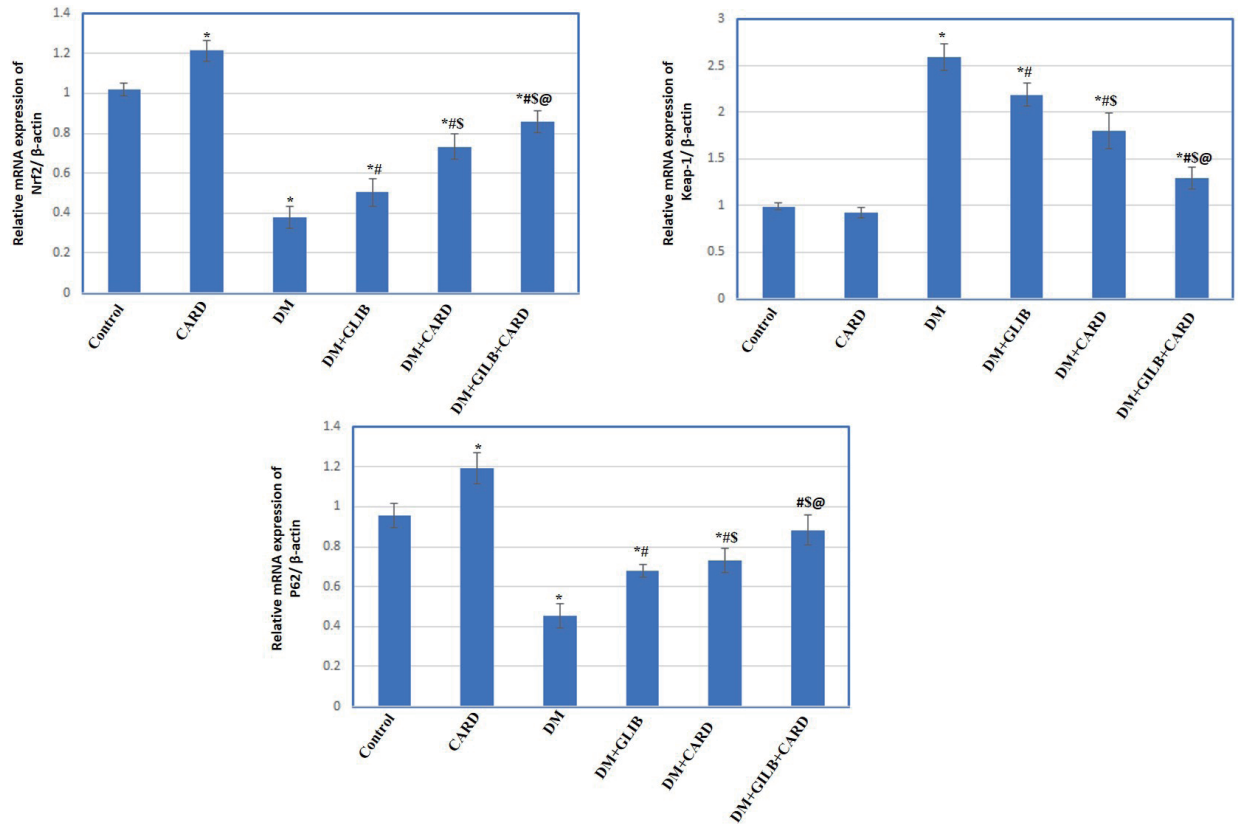

Fig. 4. Effect of cardamonin on the testicular mRNA expression of Nrf2, Keap-1 and $\mathbf{p} 62$ in different experimental groups. Values are presented as mean $\pm S D$. CARD, normal rats treated with cardamonin; $\mathrm{DM}$, untreated diabetic group; DM + GLIB, diabetic rats treated with glibenclamide; $D M+C A R D$, diabetic rats treated with cardamonin; $\mathrm{DM}+\mathrm{GLIB}$ + CARD, diabetic rats treated with both glibenclamide and cardamonin. Tests used: One-way ANOVA followed by posthoc Tukey's test. $\mathrm{p}<0.001$. *Represents significance compared with the control group; "represents significance compared with the DM group; ${ }^{5}$ represents significance compared with the DM + GLIB group; ${ }^{\circledR}$ represents significance compared with the DM + CARD group. when compared with the oxidation results in the control.

\section{Effect of CARD on the gene expression of Nrf2, Keap- 1 , and p62}

The data presented in Fig. 4 show a significant decrease in the
mRNA levels of Nrf2 and p62 $(\mathrm{p}<0.001)$ concomitant with a significant increase in the mRNA level of Keap-1 $(\mathrm{p}<0.001)$ in the untreated diabetic rat testicles as compared with the normal control results. Conversely, the mRNA levels of Nrf2 and p62 were significantly upregulated, along with a significant downregulation of the mRNA levels of Keap-1, in all diabetic treated 

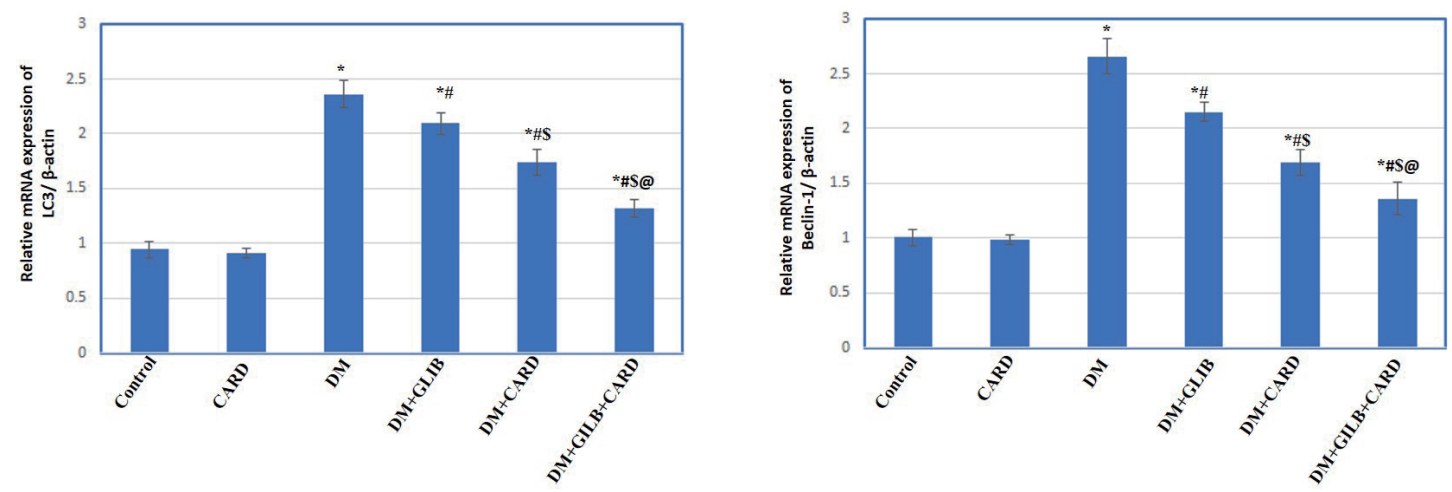

Fig. 5. Effect of cardamonin on the testicular mRNA expression of autophagy markers (LC3 and beclin-1) in different experimental groups. Values are presented as mean \pm SD. CARD, normal rats treated with cardamonin; DM, untreated diabetic group; DM + GLIB, diabetic rats treated with glibenclamide; DM + CARD, diabetic rats treated with cardamonin; DM + GLIB + CARD, diabetic rats treated with both glibenclamide and cardamonin. Tests used: One-way ANOVA followed by post-hoc Tukey's test. $p<0.001$. *Represents significance compared with the control group; "represents significance compared with the DM group; ${ }^{\lessgtr}$ represents significance compared with the DM + GLIB group; ${ }^{\circledR}$ represents significance compared with the $\mathrm{DM}+\mathrm{CARD}$ group.
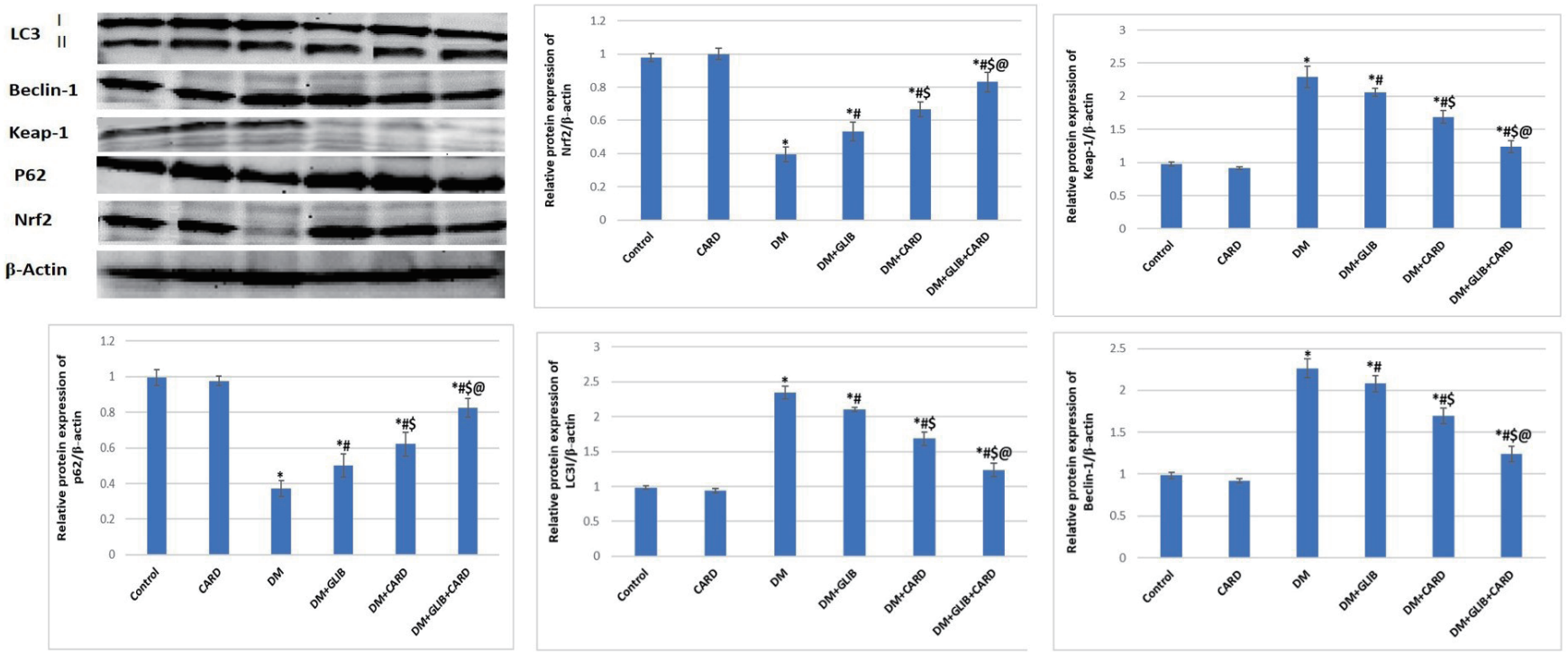

Fig. 6. Effect of cardamonin on the testicular protein expression of Nrf2, Keap-1, p62 and autophagy markers in different experimental groups. The testicular expression of Nrf2, Keap-1, p62 and autophagy markers (LC3, beclin-1) proteins was detected by western blotting assay. Values are presented as mean $\pm S D$. CARD, normal rats treated with cardamonin; DM, untreated diabetic group; DM + GLIB, diabetic rats treated with glibenclamide; DM + CARD, diabetic rats treated with cardamonin; DM + GLIB + CARD, diabetic rats treated with both glibenclamide and cardamonin. Tests used: One-way ANOVA followed by post-hoc Tukey's test. $p<0.001$. *Represents significance compared with the control group; "represents significance compared with the DM group; ${ }^{\$}$ represents significance compared with the DM + GLIB group; ${ }^{\circledR}$ represents significance compared with the DM + CARD group.

groups relative to the untreated diabetic rats. In comparison with the single treatment groups, the rats that received the combined treatment showed the best effect. Administration of CARD to the normal non-diabetic rats was associated with a significant increase in the mRNA levels of Nrf2 and p62 and a significant decrease in the mRNA level of Keap-1 when compared with the control group.

\section{Effect of CARD on the protein expression of Nrf2, Keap-1, and p62}

In addition, the testicular expression of Nrf2, p62 and Keap1 was examined by Western blot assay, as shown in Fig. 6. Keap-1 was significantly increased, while the levels of both Nrf2 and p62 were markedly decreased in the untreated diabetic group relative to the control rats $(\mathrm{p}<0.001)$. However, the CARD-treated diabetic groups showed marked increases in the protein levels of both Nrf2 and p62 ( $<$ 0.001) and significant decreases in Keap-1 
protein levels in comparison with the untreated diabetic group ( $\mathrm{p}$ $<0.001)$. The normal non-diabetic rats that received CARD had non-significant changes in these proteins levels as compared with the control group.

\section{Effect of CARD on the expression of autophagy related genes markers}

The results shown in Fig. 5 reveal a significant increase in the mRNA levels of LC3 and beclin-1 in the untreated diabetic rats' testicles when compared with the normal control results. On the other hand, the diabetic rats treated with CARD, either alone or combined with GLIB, showed a marked decrease in the expression of LC3-I and beclin-1 when compared with the non-treated diabetic rats. Furthermore, administration of CARD to the normal non-diabetic rats did not produce significant changes in the expression of either gene relative to the control results.

\section{Effect of CARD on the gene expression of autophagy related proteins markers}

Moreover, the expression of autophagy-associated proteins in the testes was detected using Western blotting, as shown in Fig. 6. LC3-I and beclin-1 protein levels were significantly upregulated in the untreated DM group when compared with control rats $(\mathrm{p}<$ 0.001). In contrast, the diabetic groups treated with CARD, either alone or combined with GLIB, exhibited a significant decrease in the levels of these autophagic proteins relative to those of the nontreated diabetic rats. In addition, the administration of CARD to the normal non-diabetic rats did not produce significant changes in the expression of either protein relative to the control group.

\section{Effect of CARD on the mRNA levels of testicular GLUT-8}

Fig. 7 demonstrates testicular changes in GLUT-8 mRNA levels. The results showed a significant decrease in the expression of GLUT-8 in the diabetic rats in comparison with the control group. In contrast, when compared with the non-treated diabetic rats, the CARD-treated diabetic groups showed marked increase in GLUT-8 expression, while normal non-diabetic rats that were administered CARD did not show any significant change in GLUT-8 expression as compared with the control group.

\section{Effect of CARD on the testicular morphology}

Histological assessment of the testicular tissue from untreated diabetic rats showed that seminiferous tubules were atrophied, along with the loss of testicular cells and disappearance of spermatids in the seminiferous tubular lumen, as shown in Fig. 8C. However, diabetic animals treated with CARD showed a moderate attenuation in the degree of seminiferous tubule and Leydig cell degeneration, and there was a reappearance of spermatids in the lumen, as illustrated in Fig. 8E. Furthermore, its combination with a conventional oral antidiabetic drug (GLIB) provided optimal protection against testicular damage in diabetic rats, and the testicular tissue appeared to be relatively normal, as presented in Fig. 8F.

\section{Effect of CARD on the testicular apoptotic marker (caspase-3)}

Fig. 9C shows a significant increase in the caspase-3 immunoreactive cells in the untreated diabetic testicular tissue as compared with the non-diabetic groups (Fig. 9A, B). However, the treatment of diabetic rats with CARD (Fig. 9E) revealed that the labelling index of the caspase-3-stained area was markedly lower than that of the untreated diabetic rats. The maximum decrease in the immunoreactive stain was found in the combined treatment group, as shown in Fig. 9F.

\section{DISCUSSION}

Infertility in young diabetic patients has become a global concern. However, to date, no treatment has been shown to effectively improve testicular dysfunctions induced by T2DM. Thus, finding a treatment for this condition remains an urgent priority. Therefore, the present study was conducted to evaluate the hypoglycemic effects of CARD on diabetic male rats and its pos-

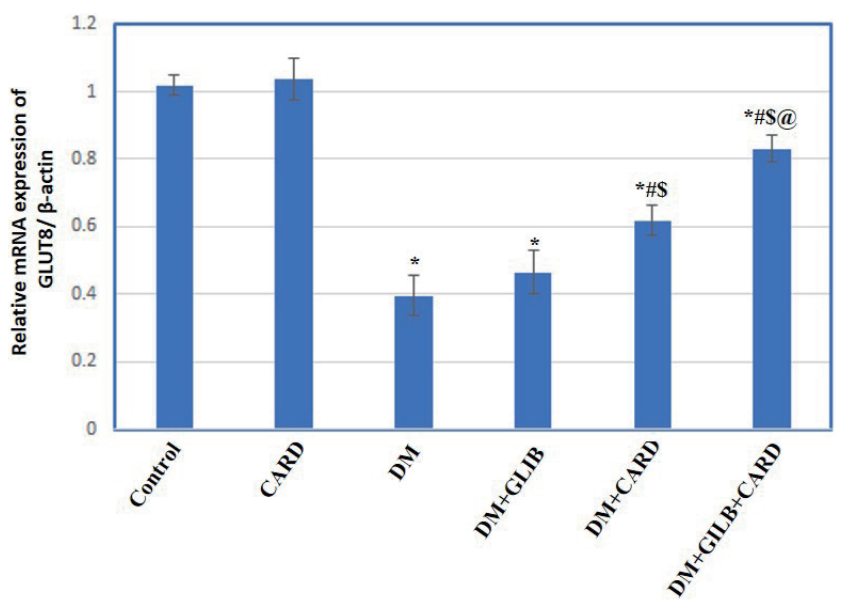

Fig. 7. Effect of cardamonin on testicular glucose transporter-8 (GLUT-8) mRNA expression in different experimental groups. Values are presented as mean $\pm S D$. CARD, normal rats treated with cardamonin; DM, untreated diabetic group; $D M+G L I B$, diabetic rats treated with glibenclamide; DM + CARD, diabetic rats treated with cardamonin; $\mathrm{DM}+\mathrm{GLIB}+\mathrm{CARD}$, diabetic rats treated with both glibenclamide and cardamonin. Tests used: One-way ANOVA followed by post-hoc Tukey's test. $p<0.001$. * Represents significance compared with the control group; "represents significance compared with the DM group; ${ }^{5}$ represents significance compared with the DM + GLIB group; ${ }^{\circledR}$ represents significance compared with the DM + CARD group. 

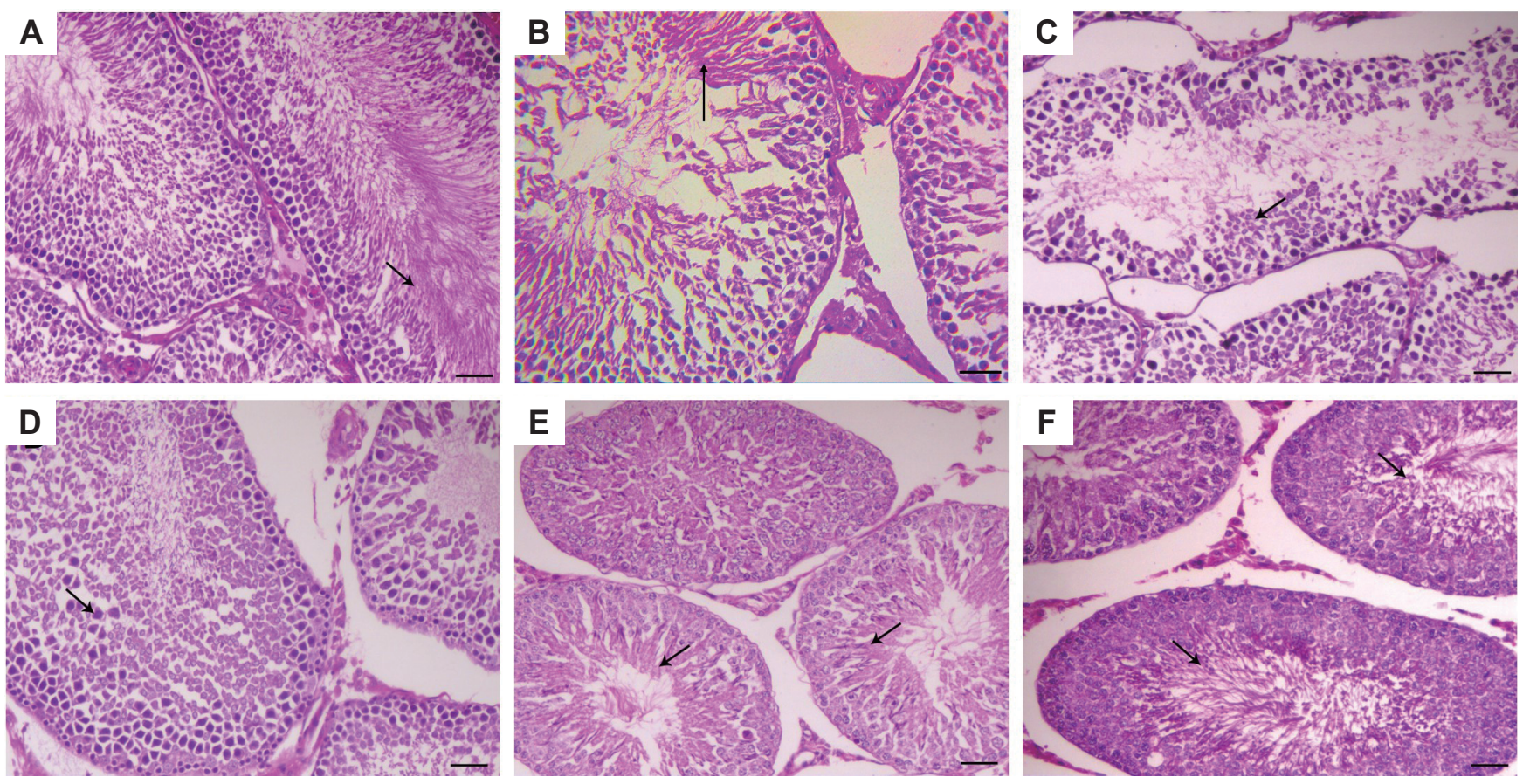

Fig. 8. Effect of cardamonin on histopathological testicular changes in different experimental groups. Testis of the control group showing normal seminiferous tubules lined with normal spermatogenic cells with the presence of numerous free spermatids in the lumen (arrow). (B) Testis of the CARD group showing normal seminiferous tubules lined with normal spermatogenic cells with the presence of numerous free spermatids in the lumen (arrow). (C) Testis of untreated DM rats showing a marked loss of spermatogenic epithelial layers and damaged appearance of the basal layer with the complete loss of spermatids in the lumen of seminiferous tubules (arrow). (D) Testis of the DM + GLIB group showing a decrease in the degenerative changes within the spermatogenic epithelial layers (arrow). (E) Testis of the DM + CARD group showing moderate restoration of the spermatogenic epithelial layers with mild appearance of spermatids (arrows). (F) Testis of the DM + GLIB + CARD group showing marked improvement in the spermatogenic epithelial layers with numerous spermatids (arrows). H\&E, 200x, bar $=50 \mu \mathrm{m}$. CARD, normal rats treated with cardamonin; DM, untreated diabetic group; $D M+G L I B$, diabetic rats treated with glibenclamide; $D M+C A R D$, diabetic rats treated with cardamonin; $D M+G L I B+C A R D$, diabetic rats treated with both glibenclamide and cardamonin.

sible ameliorative effect on diabetic testicular dysfunction and to demonstrate its possible intracellular pathways. Notably, none of the normal rats that received CARD alone exhibited any clinical lesions or testicular damage throughout the study, indicating the relative safety of CARD administration.

In the present study, the induction of T2DM was performed according to the method of AL-Megrin et al. [21] by administering HFD in order to induce insulin resistance, followed by a low dose of STZ $(35 \mathrm{mg} / \mathrm{kg})$ to destroy the islet cells. The results revealed a significant increase in blood glucose and HOMA-IR and a marked decrease in serum insulin levels. Moreover, a study performed by Feng et al. [39] demonstrated that the serum insulin level was elevated in the early stage of T2DM, playing a compensatory role in response to insulin resistance. However, the level of insulin gradually decreases in parallel with the progression of diabetes since pancreatic $\beta$ cells undergo massive destruction. Our results indicate that the administration of CARD ameliorates all of these changes, suggesting its hypoglycemic property, together with improvements in HOMA-IR, which could be explained by its upregulating effect on the GLUT8 mRNA level in the testicular tissue. In agreement with our results, Yamamoto et al. [18] also reported that CARD could enhance glucose uptake by inducing
GLUT4 translocation in L6 myotubes.

In the current study, the rats' body weights were decreased in the DM group; Ozdemir et al. [40] attributed the reduction in body weight to the breakdown of tissue protein in diabetic rats. Moreover, we observed a significant decrease in the testicular weights of untreated diabetic rats, which was associated with reduced sperm count and motility, as determined by histopathological examination. Along with these alterations, reduced levels of testosterone, FSH and LH were also observed in the untreated diabetic group. Our findings can be explained by a previous study that reported the negative effects of experimentally induced diabetes on the functions of the reproductive system and disturbances of the hypothalamus-pituitary-gonadal axis [41]. In addition, Kianifard et al. [41] found a strong correlation between FSH and insulin levels; the decreased insulin level occurred with a sharp decrease in the level of FSH, which acts synergistically with LH to stimulate testosterone synthesis. Furthermore, it was reported that the number of LH binding sites in Leydig cells was drastically lowered in diabetic rats [40]. Taken together, the high level of blood glucose, low level of insulin and reduction in gonadotropins that were observed in our untreated diabetic rats could explain the decrease in both serum testosterone and sperm count. 

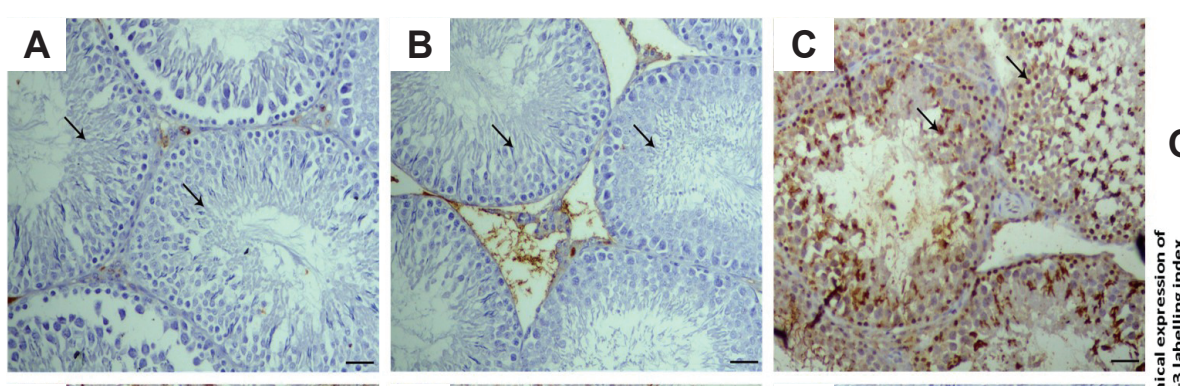

G
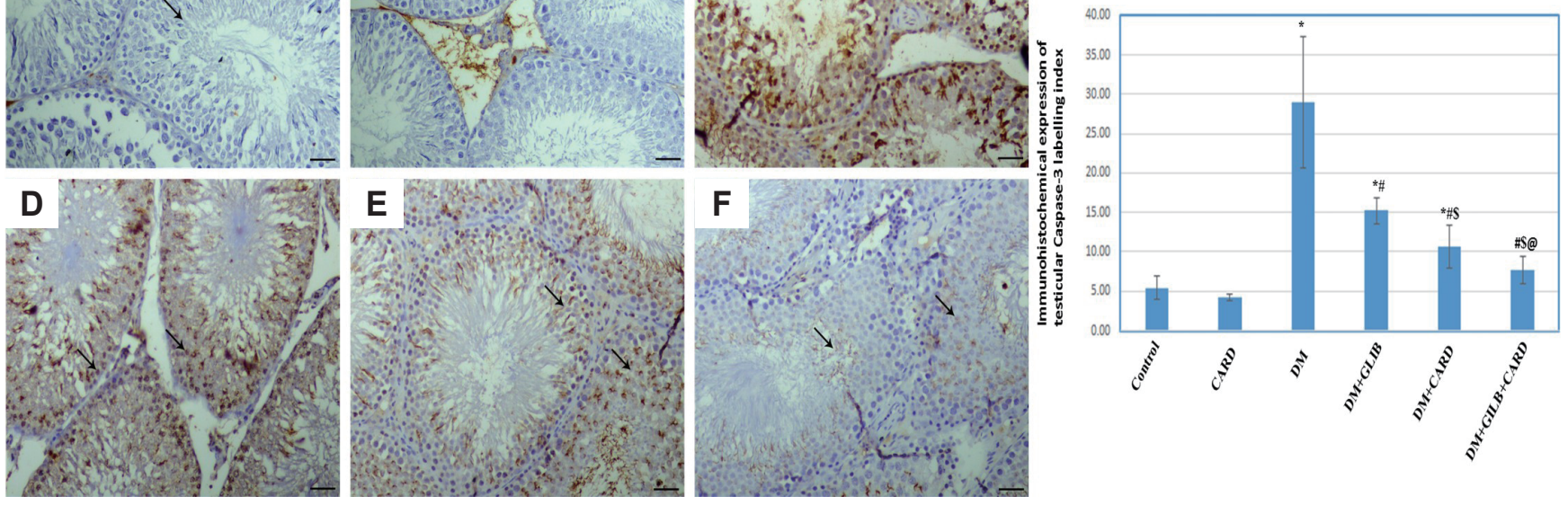

Fig. 9. Effect of cardamonin on the immunohistochemical testicular expression of an apoptotic marker (caspase-3) in different experimental groups. Immunohistochemical stain, 200x, bar $=50 \mu \mathrm{m}$. (A) Testis of the control group showing mild expression of caspase-3 antibody (arrows). (B) Testis of the CARD group showing little expression of caspase-3 antibody (arrows). (C) Testis of the untreated DM group showing marked expression of caspase-3 antibody in the spermatogenic cells of seminiferous tubules (arrows). (D) Testis of the DM + GLIB group showing a mild decrease in the expression of caspase-3 antibody in spermatogenic cells (arrows). (E) Testis of the DM + CARD group showing a moderate decrease in the expression of caspase-3 antibody in spermatogenic cells (arrows). (F) Testis of the DM + GLIB + CARD group showing a marked decrease in the expression of caspase-3 antibody in spermatogenic cells (arrows). (G) Results showing a significant increase in the caspase-3 labelling index in the untreated diabetic testicular tissue in comparison with the control. Treatment of diabetic rats with CARD produced a marked decrease in the labelling index of the caspase-3-stained area as compared with the untreated diabetic group. The maximum decrease in the immunoreactive stain was found in the DM + GLIB + CARD group when compared with the other treated diabetic groups. CARD, normal rats treated with cardamonin; DM, untreated diabetic group; $\mathrm{DM}+\mathrm{GLIB}$, diabetic rats treated with glibenclamide; DM + CARD, diabetic rats treated with cardamonin; DM + GLIB + CARD, diabetic rats treated with both glibenclamide and cardamonin. *Represents significance compared with the control group; ${ }^{*}$ represents significance compared with the DM group; ${ }^{\$}$ represents significance compared with the DM + GLIB group; ${ }^{\circledR}$ repre-sents significance compared with the DM + CARD group.

Importantly, CARD was able to attenuate testicular damage: the diminished weight loss of the testes, increased concentrations of sex hormones, preservation of spermatogenic epithelia layers and reappearance of spermatids in all CARD-treated groups suggest its protective role.

Several studies have reported that oxidative stress is a common feature and major factor of testicular dysfunction induced by T2DM $[42,43]$. In line with those studies, our findings demonstrated that the non-treated diabetic rats exhibited a decrease in antioxidant enzyme activities and impaired cellular redox balance, which promote oxidative stress. This elevation of testicular oxidative stress markers and the decreased levels of pituitary gonadotropins could explain the marked decrease in key testicular $\Delta^{5}, 3 \beta$-HSD and $17 \beta$-HSD enzyme activities. In contrast, the increased production of TBARS and decreased activity of GSH, SOD and CAT were reversed by the administration of CARD, suggesting its potent antioxidant activity. The restoration of these key androgenic enzyme activities in diabetic rats provides sufficient evidence for the protective effect of CARD against the initiation and progression of diabetes-induced testicular dysfunction.

The master regulator of redox status, Nrf2, is controlled by Keap-1. Under normal conditions, Nrf2 is sequestered by Keap-1, which results in its rapid degradation. Inhibition of Keap-1, therefore, prevents Nrf2 degradation, allowing the latter to translocate into the nucleus and upregulate the expression of targeted antioxidant genes [44]. Komatsu and colleagues [45] have also shown that the autophagy-related protein $\mathrm{p} 62$ activates $\mathrm{Nrf} 2$ by competitively combining with Keap-1. The present study suggests that the oxidative effect of diabetes in testicular tissue may be mediated by a decrease in the expression of p62, which leads to the downregulation of Nrf2 by enhancing the expression of Keap-1. Interestingly, treatment with CARD increased the expression level of p62, which interferes with the Nrf2/Keap-1 interaction in diabetic testicular tissue. These results indicate that CARD is capable of inhibiting Keap-1, contributing to an increase in Nrf2 expression and leading to the enhanced activity of critical antioxidant enzymes, along with a significant decrease in the end products of lipid peroxidation (TBARS). The antioxidant property of CARD observed in this study may be attributed to its polyphenolic components.

The relationship between diabetes and testicular autophagy remains to be clarified. Autophagy is a lysosomal degradation pathway in cells, and it plays a very important role in eliminating cytotoxic protein aggregates and damaged organelles to maintain intracellular homeostasis [46]. However, previous experimental 
studies have confirmed that excessive testicular production of ROS can induce an abnormal increase in autophagy, which can contribute to diabetic testicular injury [47-49]. Consistent with Su and his coworkers' study [50], we found that expression of the autophagic markers LC3 and beclin-1 was significantly upregulated in untreated diabetic rats. However, administration of CARD significantly decreased their levels in diabetic testes. These results suggest that the protective effects of CARD against diabetic testicular damage may be ascribed to its regulating effect on autophagy in testicular cells.

Although apoptosis is a natural phenomenon in all multicellular organisms, accelerated apoptosis plays a vital role in the development of diabetic complications [51]. Wong et al. [52] reported that hyperglycemia affects apoptosis-controlling genes. Consistent with this previous finding, the present study detected a significant increase in the expression of caspase- 3 immunoreactive cells in the testicles of untreated diabetic group, which confirms the apoptosis of testicular germ cells. Increased ROS and decreased production of testosterone, which were observed in our experiment, may explain this marked increase in the testicular apoptotic marker in the untreated diabetic rats [53,54]. Moreover, a reduction in FSH and LH leads to apoptosis in germinal cells that have testosterone receptors [55]. All of these deleterious effects of diabetes on testicles were markedly apparent in the histopathological findings, which revealed severe degeneration of the spermatogenic layers and the disappearance of spermatids. On the other hand, we noticed a significant decrease in the testicular expression of caspase-3 immunoreactive cells in CARD-treated diabetic rats, as well as the significant restoration of the spermatogenic epithelium and numerous spermatids, which may suggest its powerful anti-apoptotic effect.

The present study shows that CARD alleviates testicular dysfunction in type 2-induced diabetes in male rats through various mechanisms. Our results suggest that the hypoglycemic effect of CARD occurs through the upregulation of testicular GLUT8. It also results in a strong improvement in the cellular redox balance via activation of Nrf2 through p62-dependent testicular Keap1 degradation. Moreover, reduces testicular apoptosis and autophagy-related gene and protein levels. These beneficial effects of CARD were potentiated by its co-administration with GLIB, suggesting its possible complementary effect. Therefore, CARD alone or in combination with conventional anti-diabetic drugs may help to protect adult males from destructive diabetic testicular complications. Further extensive research needs to be performed to confirm this activity in animal models as well as human trials.

\section{ACKNOWLEDGEMENTS}

The authors would like to extend their appreciation to the Deanship of Scientific Research at King Khalid University, Saudi
Arabia, for funding this project through the research group program under grant number (R.G.P.1/217/41).

The Medical Physiology Department and Medical Experimental Research Center (MERC), Faculty of Medicine, Mansoura University, Egypt, are acknowledged for their contribution to the experimental part of the present study. The authors would also like to express their gratitude to King Khalid University, Saudi Arabia, for providing administrative and technical support.

\section{CONFLICTS OF INTEREST}

The authors declare no conflicts of interest.

\section{REFERENCES}

1. Olokoba AB, Obateru OA, Olokoba LB. Type 2 diabetes mellitus: a review of current trends. Oman Med J. 2012;27:269-273.

2. Ciresi A, Amato MC, Criscimanna A, Mattina A, Vetro C, Galluzzo A, D'Acquisto G, Giordano C. Metabolic parameters and adipokine profile during GH replacement therapy in children with GH deficiency. Eur J Endocrinol. 2007;156:353-360.

3. Ding GL, Liu Y, Liu ME, Pan JX, Guo MX, Sheng JZ, Huang HF. The effects of diabetes on male fertility and epigenetic regulation during spermatogenesis. Asian J Androl. 2015;17:948-953.

4. Maresch CC, Stute DC, Alves MG, Oliveira PF, de Kretser DM, Linn T. Diabetes-induced hyperglycemia impairs male reproductive function: a systematic review. Hum Reprod Update. 2018;24:86-105.

5. Kautzky-Willer A, Harreiter J, Pacini G. Sex and gender differences in risk, pathophysiology and complications of type 2 diabetes mellitus. Endocr Rev. 2016;37:278-316.

6. Han XX, Jiang YP, Liu N, Wu J, Yang JM, Li YX, Sun M, Sun T, Zheng P, Jian-Qiang Yu. Protective effects of Astragalin on spermatogenesis in streptozotocin-induced diabetes in male mice by improving antioxidant activity and inhibiting inflammation. Biomed Pharmacother. 2019;110:561-570.

7. Sarkar R, Ghosh P, Tripathy A, Ghosh D. Correction of diabetesinduced testicular dysfunction by a hydro-methanol (60:40) extract of Curcuma amada rhizomes: a dose-dependent study. J Food Biochem. 2019;43:e12829.

8. Demirtas L, Guclu A, Erdur FM, Akbas EM, Ozcicek A, Onk D, Turkmen K. Apoptosis, autophagy \& endoplasmic reticulum stress in diabetes mellitus. Indian J Med Res. 2016;144:515-524.

9. Las G, Shirihai OS. The role of autophagy in $\beta$-cell lipotoxicity and type 2 diabetes. Diabetes Obes Metab. 2010;12 Suppl 2:15-19.

10. Rivera JF, Costes S, Gurlo T, Glabe CG, Butler PC. Autophagy defends pancreatic $\beta$ cells from human islet amyloid polypeptideinduced toxicity. J Clin Invest. 2014;124:3489-3500.

11. Abe H, Uchida T, Hara A, Mizukami H, Komiya K, Koike M, Shigihara N, Toyofuku Y, Ogihara T, Uchiyama Y, Yagihashi S, Fujitani $\mathrm{Y}$, Watada H. Exendin-4 improves $\beta$-cell function in autophagydeficient $\beta$-cells. Endocrinology. 2013;154:4512-4524.

12. Prabhakar PK, Doble M. Effect of natural products on commercial oral antidiabetic drugs in enhancing 2-deoxyglucose uptake by 3T3L1 adipocytes. Ther Adv Endocrinol Metab. 2011;2:103-114. 
13. Lin YM, Zhou Y, Flavin MT, Zhou LM, Nie W, Chen FC. Chalcones and flavonoids as anti-tuberculosis agents. Bioorg Med Chem. 2002;10:2795-2802.

14. Yang EB, Guo YJ, Zhang K, Chen YZ, Mack P. Inhibition of epidermal growth factor receptor tyrosine kinase by chalcone derivatives. Biochim Biophys Acta. 2001;1550:144-152.

15. Tomecková V, Perjési P, Guzy J, Kusnír J, Chovanová Z, Chavková Z, Mareková M. Comparison of effect of selected synthetic chalcone analogues on mitochondrial outer membrane determined by fluorescence spectroscopy. J Biochem Biophys Methods. 2004;61:135141.

16. Orlikova B, Tasdemir D, Golais F, Dicato M, Diederich M. Dietary chalcones with chemopreventive and chemotherapeutic potential. Genes Nutr. 2011;6:125-147.

17. Tram LH, Giang PM, Son PT. Biologically active phenolic constituents from Alpinia gagnepainii K. Schum. (Zingiberaceae). Vietnam JChem. 2007;45:126-130.

18. Yamamoto N, Kawabata K, Sawada K, Ueda M, Fukuda I, Kawasaki K, Murakami A, Ashida H. Cardamonin stimulates glucose uptake through translocation of glucose transporter-4 in L6 myotubes. Phytother Res. 2011;25:1218-1224.

19. Qi W, Boliang W, Xiaoxi T, Guoqiang F, Jianbo X, Gang W. Cardamonin protects against doxorubicin-induced cardiotoxicity in mice by restraining oxidative stress and inflammation associated with Nrf2 signaling. Biomed Pharmacother. 2020;122:109547.

20. Ohadoma SC, Michael HU. Effects of co-administration of methanol leaf extract of Catharanthus roseus on the hypoglycemic activity of metformin and glibenclamide in rats. Asian Pac J Trop Med. 2011;4:475-477.

21. Al-Megrin WA, El-Khadragy MF, Hussein MH, Mahgoub S, AbdelMohsen DM, Taha H, Bakkar AAA, Abdel Moneim AE, Amin HK. Green coffea arabica extract ameliorates testicular injury in highfat diet/streptozotocin-induced diabetes in Rats. J Diabetes Res. 2020;2020:6762709.

22. Zhang M, Lv XY, Li J, Xu ZG, Chen L. The characterization of highfat diet and multiple low-dose streptozotocin induced type 2 diabetes rat model. Exp Diabetes Res. 2008;2008:704045.

23. Zhou D, Yang Q, Tian T, Chang Y, Li Y, Duan LR, Li H, Wang SW. Gastroprotective effect of gallic acid against ethanol-induced gastric ulcer in rats: Involvement of the $\mathrm{Nrf} 2 / \mathrm{HO}-1$ signaling and antiapoptosis role. Biomed Pharmacother. 2020;126:110075.

24. Muniyappa R, Chen H, Muzumdar RH, Einstein FH, Yan X, Yue LQ, Barzilai N, Quon MJ. Comparison between surrogate indexes of insulin sensitivity/resistance and hyperinsulinemic euglycemic clamp estimates in rats. Am J Physiol Endocrinol Metab. 2009;297:E1023-E1029.

25. Zhu D, Li X, Macrae VE, Simoncini T, Fu X. Extragonadal effects of follicle-stimulating hormone on osteoporosis and cardiovascular disease in women during menopausal transition. Trends Endocrinol Metab. 2018;29:571-580.

26. Stoléru SG, Ennaji A, Cournot A, Spira A. LH pulsatile secretion and testosterone blood levels are influenced by sexual arousal in human males. Psychoneuroendocrinology. 1993;18:205-218.

27. Chen A, Bookstein JJ, Meldrum DR. Diagnosis of a testosteronesecreting adrenal adenoma by selective venous catheterization. Fertil Steril. 1991;55:1202-1203.

28. Biswas NM, Sen Gupta R, Chattopadhyay A, Choudhury GR,
Sarkar M. Effect of atenolol on cadmium-induced testicular toxicity in male rats. Reprod Toxicol. 2001;15:699-704.

29. Ohkawa H, Ohishi N, Yagi K. Assay for lipid peroxides in animal tissues by thiobarbituric acid reaction. Anal Biochem. 1979;95:351358.

30. Aebi H. Catalase in vitro. Methods Enzymol. 1984;105:121-126.

31. Beutler E, Duron O, Kelly BM. Improved method for the determination of blood glutathione. J Lab Clin Med. 1963;61:882-888.

32. Kakkar P, Das B, Viswanathan PN. A modified spectrophotometric assay of superoxide dismutase. Indian J Biochem Biophys. 1984;21:130-132.

33. Klinefelter GR, Gray LE Jr, Suarez JD. The method of sperm collection significantly influences sperm motion parameters following ethane dimethanesulphonate administration in the rat. Reprod Toxicol. 1991;5:39-44.

34. Zemjanis R. Collection and evaluation of semen. In: Zemjanis R, editor. Diagnostic and therapeutic techniques in animal reproduction. 3rd ed. Baltimore: Williams and Wilson Co.; 1970. p.139-156.

35. Saber S, Khalil RM, Abdo WS, Nassif D, El-Ahwany E. Olmesartan ameliorates chemically-induced ulcerative colitis in rats via modulating NFkB and Nrf-2/HO-1 signaling crosstalk. Toxicol Appl Pharmacol. 2019;364:120-132.

36. Muller PY, Janovjak H, Miserez AR, Dobbie Z. Processing of gene expression data generated by quantitative real-time RT-PCR. Biotechniques. 2002;32:1372-1374, 1376, 1378-1379.

37. Livak KJ, Schmittgen TD. Analysis of relative gene expression data using real-time quantitative PCR and the $2^{-\triangle \Delta C T}$ method. Methods. 2001;25:402-408.

38. Tabecka-Lonczynska A, Mytych J, Solek P, Koziorowski M. Autophagy as a consequence of seasonal functions of testis and epididymis in adult male European bison (Bison bonasus, Linnaeus 1758). Cell Tissue Res. 2020;379:613-624.

39. Feng XT, Tang SY, Jiang YX, Zhao W. Anti-diabetic effects of zhuoduqing formula, a Chinese herbal decoction, on a rat model of type 2 diabetes. Afr J Tradit Complement Altern Med. 2017;14:4250 .

40. Ozdemır O, Akalın PP, Baspınar N, Hatıpoglu F. Pathological changes in the acute phase of streptozotocin-induced diabetic rats. Bull Vet Inst Pulawy. 2009;53:783-790.

41. Kianifard D, Sadrkhanlou RA, Hasanzadeh S. The ultrastructural changes of the sertoli and leydig cells following streptozotocin induced diabetes. Iran J Basic Med Sci. 2012;15:623-635.

42. Kanter M, Aktas C, Erboga M. Curcumin attenuates testicular damage, apoptotic germ cell death, and oxidative stress in streptozotocin-induced diabetic rats. Mol Nutr Food Res. 2013;57:1578-1585.

43. Fernandes GS, Fernandez CD, Campos KE, Damasceno DC, Anselmo-Franci JA, Kempinas WD. Vitamin C partially attenuates male reproductive deficits in hyperglycemic rats. Reprod Biol Endocrinol. 2011;9:100.

44. Vomund S, Schäfer A, Parnham MJ, Brüne B, von Knethen A. $\mathrm{Nrf2}$, the master regulator of anti-oxidative responses. Int J Mol Sci. 2017;18:2772.

45. Komatsu M, Kageyama S, Ichimura Y. p62/SQSTM1/A170: physiology and pathology. Pharmacol Res. 2012;66:457-462.

46. Huang C, Lin MZ, Cheng D, Braet F, Pollock CA, Chen XM. KCa3.1 mediates dysfunction of tubular autophagy in diabetic kidneys via PI3k/Akt/mTOR signaling pathways. Sci Rep. 2016;6:23884. 
47. Wei Y, Cao XN, Tang XL, Shen LJ, Lin T, He DW, Wu SD, Wei GH. Urban fine particulate matter (PM2.5) exposure destroys bloodtestis barrier (BTB) integrity through excessive ROS-mediated autophagy. Toxicol Mech Methods. 2018;28:302-319.

48. Yi WEI, Xiang-Liang T, Yu Z, Bin L, Lian-Ju S, Chun-Lan L, Tao LIN, Da-Wei HE, Sheng-de WU, Guang-Hui WEI. DEHP exposure destroys blood-testis barrier (BTB) integrity of immature testes through excessive ROS-mediated autophagy. Genes Dis. 2018;5:263274.

49. Huang W, Cao Z, Zhang J, Ji Q, Li Y. Aflatoxin B promotes autophagy associated with oxidative stress-related PI3K/AKT/mTOR signaling pathway in mice testis. Environ Pollut. 2019;255(Pt 2):113317.

50. Su J, Zhou L, Kong X, Yang X, Xiang X, Zhang Y, Li X, Sun L. Endoplasmic reticulum is at the crossroads of autophagy, inflammation, and apoptosis signaling pathways and participates in the pathogenesis of diabetes mellitus. J Diabetes Res. 2013;2013:193461.

51. Okouchi M, Okayama N, Aw TY. Preservation of cellular glutathione status and mitochondrial membrane potential by $\mathrm{N}$-acetylcys- teine and insulin sensitizers prevent carbonyl stress-induced human brain endothelial cell apoptosis. Curr Neurovasc Res. 2009;6:267278.

52. Wong VY, Keller PM, Nuttall ME, Kikly K, DeWolf WE Jr, Lee D, Ali SM, Nadeau DP, Grygielko ET, Laping NJ, Brooks DP. Role of caspases in human renal proximal tubular epithelial cell apoptosis. Eur J Pharmacol. 2001;433:135-140.

53. Tang XY, Zhang Q, Dai DZ, Ying HJ, Wang QJ, Dai Y. Effects of strontium fructose 1,6-diphosphate on expression of apoptosisrelated genes and oxidative stress in testes of diabetic rats. Int J Urol. 2008;15:251-256.

54. Boekelheide K, Fleming SL, Johnson KJ, Patel SR, Schoenfeld HA. Role of Sertoli cells in injury-associated testicular germ cell apoptosis. Proc Soc Exp Biol Med. 2000;225:105-115.

55. Cai L, Chen S, Evans T, Deng DX, Mukherjee K, Chakrabarti S. Apoptotic germ-cell death and testicular damage in experimental diabetes: prevention by endothelin antagonism. Urol Res. 2000;28:342-347. 